\title{
Effect of continuous treatment with topical corticosteroid on episodic viral wheeze in preschool children
}

\author{
Nicola Wilson, Katherine Sloper, Michael Silverman
}

\begin{abstract}
Acute episodic wheeze related to viral infections is a common and distressing condition and treatment remains unsatisfactory. Although some benefit from the continuous use of inhaled steroids has been demonstrated in young wheezy children, their effect primarily on acute episodes has not been considered. In this study the effect of budesonide $(400 \mu \mathrm{g} / \mathrm{day})$ was assessed in a four month double blind parallel trial, in 41 children $(0 \cdot 7-6 \cdot 0$ years) with predominantly episodic viral wheeze. Analysis of the last three months showed no difference between budesonide or placebo in mean daily total symptom score (median values 0.6 and 0.63 ), episode number (mean values $2 \cdot 6$ and $2 \cdot 4$ ), or score/episode (mean value 30 and 31 ). Four months of treatment with inhaled budesonide had no effect on acute episodes of wheeze in this group of children.

(Arch Dis Child 1995; 72: 317-320)
\end{abstract}

Keywords: topical corticosteroids, preschool wheeze.

Wheezing in young children is extremely common. ${ }^{1}$ In the majority, symptoms are episodic and reported to be associated with virus infections. Treatment for this condition remains unsatisfactory with large numbers being admitted to hospital, ${ }^{23}$ especially in the winter months. Two previous studies have found small but statistically significant benefit from the additional use of short courses of high dose inhaled steroids started at the onset of acute episodes. ${ }^{4}$ The modest size of this improvement is, however, not sufficient for this to be an alternative to short courses of oral corticosteroids. Another approach for frequent, troublesome episodes, might be preventive treatment with low dose, topical corticosteroids.

The effect of continuous, prophylactic inhaled steroids to treat troublesome wheezing in preschool children has been assessed in a number of small clinical trials with most ${ }^{6-12}$ but not all ${ }^{13} 14$ reporting some benefit. The subjects in these studies have generally suffered with persistent or chronic symptoms. The trials have not specifically determined the effect of treatment on the acute episodes, but in clinical practice it is not uncommon for young children with troublesome episodic symptoms, but without intercurrent symptoms, to be started on continuous prophylactic inhaled steroid treatment.
The aim of this study was to determine the effect of four months' daily treatment with inhaled budesonide on acute episodes of wheeze associated with viral infections in preschool children. In order to avoid treating children with chronic symptoms with placebo for a prolonged period and in order to simplify the detection of acute episodes, only children with predominantly episodic symptoms were included.

\section{Methods}

SUBJECTS

Children aged 8 months-6 years were recruited from three hospital asthma clinics (Ashford in Middlesex, Ealing and Hammersmith Hospitals) on the basis of troublesome wheezing episodes associated with clinical viral infections, with a history of no or minimal symptoms between episodes. Inclusion criteria were: at least two episodes of sufficient severity to disturb sleep in the preceding three months and a parental report of benefit from topical bronchodilator treatment during acute attacks. Recruiting took place between the months of September and March.

\section{TRIAL PROTOCOL}

The trial was a parallel group, randomised, double blind comparison of budesonide $200 \mu \mathrm{g}$ twice daily and an identical placebo lasting for four months. Subjects were randomly assigned to take four puffs from active or placebo metered dose inhalers (Astra) twice daily through either a Nebuhaler (Astra), if it could be used satisfactorily, or an Aerochamber with facemask (Trudell Medical). Parents were taught to activate the trial inhaler once the spacer was in position and allow three tidal breaths for inhalation after each actuation. Entry into the trial was delayed until resolution of the most recent episode and at least four weeks after any course of oral corticosteroids. Additional bronchodilators either ipratropium bromide or $\beta_{2}$ agonists were used as needed.

The only criterion for withdrawal, apart from parental wish, was the need for bronchodilator treatment on more than four days a week between acute episodes.

ASSESSMENT

During the trial period parents kept a daily diary of night and daytime cough and wheeze (scores 0-3); activity induced respiratory 
Table 1 Subject characteristics in the two treatment groups on entry and during the trial

\begin{tabular}{lcc}
\hline & $\begin{array}{c}\text { Budesonide } \\
(n=20)\end{array}$ & $\begin{array}{c}\text { Placebo } \\
(n=20)\end{array}$ \\
\hline $\begin{array}{l}\text { On entry } \\
\text { Mean (range) age (years) }\end{array}$ & $1 \cdot 9(0 \cdot 8-6 \cdot 0)$ & $1 \cdot 9(0 \cdot 7-4 \cdot 8)$ \\
M:F & $11: 9$ & $13: 8$ \\
Mean (range) birth weight (g) & $3200(2100-4600)$ & $3200(1000-4500)$ \\
Family history (\%) & 83 & 81 \\
$\quad$ Asthma & 67 & 42 \\
Atopic disease & 17 & 33 \\
Maternal smoking (\%) & $4 \cdot 0(2-12)$ & $4 \cdot 0(2-14)$ \\
Median (range) No of attacks in preceding year & $2 \cdot 0(0-6)$ & $1 \cdot 2(0-4)$ \\
Spacers used (Aerochamber:Nebuhaler) & $16: 5$ & $16: 4$ \\
During trial & & $4(2$ children $)$ \\
Courses of oral corticosteroids & $3(2$ children) & 2 \\
Hospital admissions & 0 & 3 \\
Visits to emergency department & 4 & \\
\hline
\end{tabular}

symptoms as well as bronchodilator and other medication use was also recorded, as were symptoms suggestive of colds or infections, such as fever, runny nose, or otitis media.

Written consent was obtained from all parents and approval obtained from the hospitals' ethics committees.

\section{ANALYSIS OF RESULTS}

To allow for a delay in the preventive action of budesonide the last three months of the four month trial period have been analysed. Comparison of active and placebo treatment was made from results collected in three ways. (1) Total scores were added over three months. (2) Symptom scores were calculated during acute episodes only, including both those considered to be related to infections and those which were not; episodes were defined as two or more discrete days of symptoms, preceded and followed by at least two asymptomatic days, or on the few occasions when there were intercurrent symptoms, an episode was defined as an increase by a score of at least 1 over the preceding values lasting for at least two days. (3) Symptom scores between episodes were calculated; the number of symptomatic days between episodes has been expressed as a proportion of the total number of days not included in episodes. Bronchodilator usage was calculated as the number of puffs/day; a nebulised dose was arbitrarily counted as eight puffs.

Each outcome variable was tested for normality and validity for parametric analysis;

Table 2 Comparison of symptoms between budesonide and placebo groups

\begin{tabular}{|c|c|c|c|c|}
\hline Outcome & Budesonide & Placebo & $\begin{array}{l}95 \% \text { Confidence } \\
\text { interval of difference } \\
\text { (budesonide-placebo) }\end{array}$ & $\stackrel{p}{\text { Value }}$ \\
\hline $\begin{array}{l}\text { (1) Total } 3 \text { month period } \\
\text { Daily mean score (median) } \\
\text { Symptom free days (\%) (median) }\end{array}$ & $\begin{array}{l}0 \cdot 6 \\
73\end{array}$ & $\begin{array}{l}0.63 \\
78\end{array}$ & $\begin{array}{r}-0.4 \text { to } 0.45 \\
-11.0 \text { to } 12.0\end{array}$ & $\begin{array}{l}0 \cdot 88 \\
1 \cdot 0\end{array}$ \\
\hline $\begin{array}{l}\text { (2) Acute episodes (mean scorelepisode) } \\
\left.\text { Total score (mean }{ }^{\star}\right) \\
\text { Night cough (median) } \\
\text { Night wheeze (median) } \\
\text { Day cough (median) } \\
\text { Day wheeze (median) } \\
\text { Bronchodilator use (puffs/day) (median) } \\
\text { No of episodes (mean }{ }^{\star} \text { ) } \\
\left.\text { Episode duration (days) (mean }{ }^{\star}\right)\end{array}$ & $\begin{array}{c}30 \\
7 \cdot 8 \\
4 \cdot 0 \\
7 \cdot 5 \\
5 \cdot 1 \\
30 \\
2 \cdot 6 \\
8 \cdot 0\end{array}$ & $\begin{array}{c}31 \\
7 \cdot 3 \\
4 \cdot 0 \\
7 \cdot 6 \\
5 \cdot 0 \\
29 \\
2 \cdot 4 \\
8 \cdot 6\end{array}$ & $\begin{array}{l}-13 \cdot 1 \text { to } 15 \cdot 1 \\
-4 \cdot 5 \text { to } 3 \cdot 8 \\
-4 \cdot 0 \text { to } 2 \cdot 0 \\
-2 \cdot 5 \text { to } 5 \cdot 7 \\
-4 \cdot 5 \text { to } 2 \cdot 9 \\
-22 \cdot 1 \text { to } 9 \cdot 7 \\
-0.8 \text { to } 0 \cdot 4 \\
-3 \cdot 3 \text { to } 2 \cdot 1\end{array}$ & $\begin{array}{l}0 \cdot 8 \\
0 \cdot 9 \\
0 \cdot 8 \\
0 \cdot 5 \\
0 \cdot 83 \\
0 \cdot 32 \\
0 \cdot 6 \\
0 \cdot 67\end{array}$ \\
\hline $\begin{array}{l}\text { (3) Symptoms between episodes } \\
\text { Symptomatic days }(\%) \text { (median) } \\
\text { Daily score (median) } \\
\text { Bronchodilator use (puffs/day) (median) }\end{array}$ & $\begin{array}{l}0 \\
0 \\
0\end{array}$ & $\begin{array}{l}3 \\
1 \\
0\end{array}$ & $\begin{aligned} & 0 \text { to } 7.0 \\
& 0 \text { to } 1.0 \\
&<-0.001 \text { to }<0.001\end{aligned}$ & $\begin{array}{l}0.09 \\
0.07 \\
0 \cdot 14\end{array}$ \\
\hline
\end{tabular}

$\star$ Group mean scores compared by paired $t$ test; all other group medians compared by Mann-Whitney U test. when appropriate a paired Student's $t$ test was used. Otherwise comparisons were made using a Mann-Whitney U test. From a previous study of a similar group of children ${ }^{4}$ we had calculated that 18 children in each arm of the trial would be needed to show a $50 \%$ difference in nocturnal symptoms during acute episodes with $80 \%$ power at the $5 \%$ level.

\section{Results}

SUBJECTS

Fifty seven children were enrolled into the trial but 16 withdrew. Only six withdrawals were for respiratory reasons, three from each treatment group: five at parental instigation because of continuing acute episodes (three budesonide, one hospital admission, two placebo, one hospital admission) and one because of severe continuous symptoms (placebo). Seven failed to adhere to the trial protocol through inadequate record keeping or spacer use (four budesonide and three placebo). The remaining three were withdrawn for miscellaneous reasons (headbanging, placebo; generally miserable, budesonide; cardiac surgery, budesonide). Thus 41 children completed the trial, 20 on budesonide and 21 on placebo. The age on entry, sex ratio, and pretrial symptoms were similar in the two groups (table 1). The majority had a family history of asthma or atopic disease and their mothers smoked in $25 \%$ (table 1). Twelve children used ipratropium bromide as their bronchodilator (seven on placebo) and 16 in each group took their inhalers through an Aerochamber and facemask.

There was no difference in the distribution of month of enrolment between the two groups. During the last two months of recruitment (February and March), when fewer viral infections might be anticipated during the subsequent trial period, four were enrolled into the placebo group and six into budesonide.

\section{SYMPTOM SCORES}

\section{(1) Total three month period}

There was no significant difference in overall scores or number of symptom free days between the two groups (table 2), even if the total scores were subdivided into night cough, night wheeze, day cough, and day wheeze (budesonide:placebo median daily scores $0 \cdot 26: 0 \cdot 26, \quad 0 \cdot 14: 0 \cdot 08, \quad 0 \cdot 23: 0 \cdot 25 ; \quad 0 \cdot 1: 0 \cdot 16$ respectively). The median number of bronchodilator puffs/day was $0 \cdot 14$ on budesonide and 0.59 on placebo (not significant).

\section{(2) Acute episodes}

A total of 96 episodes were reported; 85 (89\%) were considered to be associated with clinical evidence of a virus infection. Of the 11 noninfective episodes, eight occurred in six children on placebo and three occurred in three children on budesonide. The median number of acute episodes (infective and noninfective combined) experienced was similar in each group (table 2). There was no difference 
in total score/episode or in mean scores/day during an episode for night or day symptoms or for cough or wheeze (table 2). The mean duration of episodes and quantity of additional bronchodilator usage was also similar. Two children on budesonide received a total of three courses of oral corticosteroids and two children on placebo four courses (table 1).

\section{(3) Symptoms between episodes}

Few symptoms were experienced between episodes by the majority of children. For those on budesonide, the median score was nil and on placebo 1 . The difference did not quite reach statistical significance (table 2 ).

\section{Discussion}

In this group of children with predominantly episodic viral wheeze in whom the large majority had a family history of asthma or atopic diseases, we were unable to demonstrate any benefit from four months' continuous treatment with budesonide $400 \mu \mathrm{g} /$ day. To our knowledge, there is no previous published report of the effect of inhaled steroids in preschool children selected on the basis of having predominantly episodic wheeze associated with clinical viral infections, although overall, this is by far the commonest pattern of wheeze in the preschool population.

Episodic wheeze in this age group is notoriously variable and this could make it difficult to show any benefit from therapeutic interventions in small trials. From a previous study of a similar group of children ${ }^{4}$ we had calculated that 18 children in each arm of the trial would be needed to show a $50 \%$ difference in nocturnal symptoms during acute episodes with $80 \%$ power at the $5 \%$ level. We reasoned that to justify subjecting young children with episodic symptoms to continuous treatment with an inhaled steroid, only a substantial improvement would be clinically relevant. The present results confirm the variability in symptoms in that, although differences between active and placebo were small, the $95 \%$ confidence intervals of the differences were wide (table 2). Since for some outcome measures, the upper limit of the difference between placebo and budesonide included a 50\% reduction in symptoms, we cannot say we have excluded a type 2 error with complete certainty. By the same line of reasoning we must conclude that a similar possible benefit is just as likely from placebo! The very variability of symptoms in children such as these, means in clinical practice it may be impossible to judge the real effect of any therapeutic intervention in an individual child with episodic symptoms.

In such an intermittent condition, would a trial of a longer duration be preferable? Since the symptoms are more frequent in the winter and show a marked tendency to decrease with age, it is important to demonstrate both the tendency to wheeze and to assess the effect of treatment in each child during a single winter season, which limits the possible length of such a trial. Since all children experienced at least one episode during the three month period the duration of the study period is unlikely to account for the negative results. Another possible explanation for the lack of benefit from treatment is lack of compliance with the twice daily inhaler regimen; this was not measured. A number of children were withdrawn because of an acknowledged lack of compliance, mainly in inhaler use, and the parents of those completing the study appeared to show a high degree of motivation and desire for some therapeutic intervention to alleviate their children's symptoms; although they are likely to represent a group more likely to comply with treatment than the majority of parents encountered in clinical practice, failure to give the medication regularly cannot be ruled out.

The effect of inhaled steroids on wheezing symptoms in this age group has been assessed in a number of previous studies. The majority $^{6-12}$ but not all ${ }^{1314}$ have shown a small but statistically significant improvement in some outcome measures after treatment with budesonide or beclomethasone, delivered either by metered dose inhaler and spacer device with or without facemask ${ }^{791012}$ or nebuliser. ${ }^{6811} \mathrm{~A}$ possible explanation for our negative findings is that the lung dose of budesonide was inadequate. The exact dose of an aerosol that reaches the airways is not known but is likely to be reduced in young children using a masked spacer device ${ }^{1516}$ or nebulised suspension. ${ }^{15}$ Bronchodilator studies using similar spacer devices have demonstrated efficacy ${ }^{1718}$ and a good response was also claimed by parents to bronchodilators administered during our study with the Aerochamber and the Nebuhaler. The studies reporting efficacy used a range of inhaled steroid preparations, doses, and delivery systems. In the study of Noble and colleagues $^{7}$ a smaller dose and arguably a less efficient masked spacer device was used than in the present study ${ }^{16}$ and in that of two other studies the dose and spacer device used were the same as the children in our study using a Nebuhaler. ${ }^{1012}$ Our negative findings are therefore unlikely to be related to the lung dose of budesonide, particularly as the majority of older asthmatic children respond to low doses of inhaled steroids. ${ }^{19}$

The major difference between the current study and previous ones is in the selection of subjects; in the current study children with mainly acute episodic wheeze were included whereas in others, although not clearly defined, chronic symptoms predominated. It is therefore possible that inhaled steroids prevent day to day asthma but have a lesser or no effect on acute virus related episodes. Despite the fact that our subjects had very little in the way of symptoms between acute episodes, it is in this type of symptom that the most convincing difference between the groups was found (table 2). However, there were too few symptoms in this category for a satisfactory assessment, and this was not the purpose of the trial.

The one study, which has demonstrated benefit from treatment with inhaled steroids on acute episodes of wheezing, is not exactly 
comparable and needs confirming. ${ }^{20}$ Acute wheezing episodes in infants were treated with nebulised beclomethasone for an eight week period and a reduction in the number of obstructive episodes was seen during the subsequent 12 months. This prolonged benefit is in contrast to other studies of inhaled steroids in which symptoms have been found to return on cessation of treatment. ${ }^{62122}$ Another unusual and interesting feature of this study was that upper respiratory symptoms were also reduced.

We conclude from our findings that budesonide $(400 \mu \mathrm{g} /$ day) given for a four month period has no effect on acute episodes of wheeze associated with clinical viral infections in young children. It remains to be seen whether virus related episodes experienced by those with more chronic symptoms are similarly resistant to treatment.

We acknowledge financial support from the National Asthma We acknown we are orateful to Dr Peter Husband for asking us to Campaign; we are grateful to Dr Peter Husband for asking us to
include patients from Ashford Hospital and to Astra (Sweden) include patients from Ashford
for providing the trial inhalers.

1 Strachan DP. The prevalence and natural history of wheezing in early childhood. $\mathcal{F} R$ Coll Gen Pract $1985 ; 35: 182-4$. ing in early childhood. $\mathcal{F} R$ Coll Gen Pract $1985 ; 35$ : 182-4. self referral. Arch Dis Child 1988; 63: 774-9.

3 Anderson HR. Increase in hospital admissions for childhood asthma: trends in referral, severity and readmissions from $1970-1985$ in a health region of the United Kingdom. Thorax 1989; 44: 614-9.

4 Wilson NM, Silverman M. Treatment of acute, episodic asthma in preschool children using intermittent high dose inhaled steroids at home. Arch Dis Child 1990; 65: 407-10.

5 Connett G, Lenney W. Prevention of viral induced asthma attacks using inhaled budesonide. Arch Dis Child 1993; 68: 85-7.

6 Maayan C, Itzhaki T, Bar-Yishay E, Gross S, Tail A, Godfrey $S$. The functional response to infants with persistent wheezing to nebulized beclomethasone dipropionate. Pediatr Pulmonol 1986; 2: 9-15.
7 Noble V, Ruggins NR, Everard ML, Milner AD. Inhaled budesonide for chronic wheezing under 18 months of age. Arch Dis Child 1992; 67: 285-8.

8 Ilangoven P, Pedersen S, Godfrey S, Nikander K, Noviski N, Warner JO. Treatment of severe steroid dependent preschool asthma with nebulised budesonide suspension. preschool asthma with nebulised

9 Bisgaard H, Munck SL, Nielson JP, Peterson W, Ohlsson $\mathrm{SV}$. Inhaled budesonide for treatment of recurrent wheezing in early childhood. Lancet 1990; 336: 649-51.

10 Connett GJ, Warde C, Wooler E, Lenney W. Use of budesonide in severe asthmatics aged 1-3 years. Arch Dis Child 1993; 69: 351-5.

11 Storr J, Lenney CA, Lenney W. Nebulised beclomethasone dipropionate in preschool asthma. Arch Dis Child 1986, 61: 270-3.

12 Gleeson JGA, Price JF. Controlled trial of budesonide given by the nebuhaler in preschool children with asthma. $B M \mathcal{F}$ 1988; 297: 163-6.

13 Webb MSC, Milner AD, Hiller EJ, Henry RI Nebulised beclomethasone dipropionate suspension. Arch Dis Child 1986; 61: 1108-10.

14 Van Bever HP, Schuddinck L, Wojciechowski M, Stevens WJ. Aerosolized budesonide in asthmatic infants: a double blind study. Pediatr Pulmonol 1990; 9: 177-80

15 Salmon B, Wilson NM, Silverman M. How much aerosol reaches the lungs of wheezy infants and toddlers? Arch Dis Child 1990; 65: 901-3.

16 Everard ML, Clark AR, Milner AD. Drug delivery from holding chambers with attached facemask. Arch Dis Child 1992; 67: 580-5.

17 Connet WT, Dolovich MB, Frame RA, Newhouse MT Reliable salbutamol administration in 6 to 36 month old children by means of a metered dose inhaler and Aerochamber with mask. Pediatr Pulmonol 1989; 6: 263-7.

18 Pool IB, Greenough A, Gleeson JGA, Price JF. Inhaled bronchodilator treatment via the nebuhaler in young bronchodilator treatment via the nebuhaler in your

19 Pedersen S, Hansen OR. Budesonide treatment of moderate and severe asthma in children: a dose response study. F Allergy Clin Immunol (in press)

20 Carlsen KH, Leegaard J, Larsen S, Orstavik I. Nebulised beclomethasone dipropionate in recurrent obstructive episodes after acute bronchiolitis. Arch Dis Child 1988; 63: 1428-33.

21 Waalkens HJ, Van Essen-Zandvliet EE, Hughes MB, et al. Cessation of long term treatment with inhaled corticosteroid (budesonide) in children with asthma results in rapid deterioration. Am Rev Respir Dis 1993; 148: 1252-7.

22 Vathenan AS, Knox AJ, Wisniewski A, Tattersfield AE. Time course of change in bronchial reactivity with an inhaled corticosteroid in asthma. Am Rev Respir Dis 1991; 143: $1317-21$. 